\title{
The Effect of the Type and Composition of Demand on the Influence of DSM on Power System Angular Stability
}

DOI:

10.1109/GTDAsia.2019.8715884

Document Version

Final published version

Link to publication record in Manchester Research Explorer

\section{Citation for published version (APA):}

Wang, M., Ponocko, J., \& Milanovic, J. V. (2019). The Effect of the Type and Composition of Demand on the Influence of DSM on Power System Angular Stability. In GTDA Conference 2019, IEEE

https://doi.org/10.1109/GTDAsia.2019.8715884

\section{Published in:}

GTDA Conference 2019, IEEE

\section{Citing this paper}

Please note that where the full-text provided on Manchester Research Explorer is the Author Accepted Manuscript or Proof version this may differ from the final Published version. If citing, it is advised that you check and use the publisher's definitive version.

\section{General rights}

Copyright and moral rights for the publications made accessible in the Research Explorer are retained by the authors and/or other copyright owners and it is a condition of accessing publications that users recognise and abide by the legal requirements associated with these rights.

\section{Takedown policy}

If you believe that this document breaches copyright please refer to the University of Manchester's Takedown Procedures [http://man.ac.uk/04Y6Bo] or contact uml.scholarlycommunications@manchester.ac.uk providing relevant details, so we can investigate your claim.

\section{OPEN ACCESS}




\title{
The Effect of the Type and Composition of Demand on the Influence of DSM on Power System Angular Stability
}

\author{
M. Wang, Student Member, IEEE, J.Ponoćko, Graduate Student Member, IEEE, J.V. Milanović, Fellow, IEEE \\ School of Electrical and Electronic Engineering \\ The University of Manchester, Manchester, UK \\ mengxuan.wang@postgrad.manchester.ac.uk, jelena.ponocko@manchester.ac.uk, milanovic@manchester.ac.uk
}

\begin{abstract}
Demand Side Management (DSM) is being actively considered as potentially effective way to enhance power system operational flexibility. Due to the fact that DSM changes not only total demand but also demand compositions at affected hours, it could subsequently affect system dynamic response and stability performance. This paper investigates the potential impact of DSM on power system angular stability depending on the type of demand and demand composition. The results show that the main indicators of angular stability, namely transient stability and damping of the most critical electromechanical mode, are very dependent on the type of the load model used to model demand, and on actual demand composition. All simulations are carried out in DigSILENT/PowerFactory environment using a modified version of the 68 bus NETS-NYPS test system.
\end{abstract}

Keywords - Angular stability, demand side management, demand modelling, load composition, probabilistic analysis.

\section{INTRODUCTION}

With the continuing growth in Renewable Energy Sources (RES), integration of non-linear load, and application of new control technologies and devices, modern power systems tend to operate more and more in reasonably stressed conditions [1]. Demand side management (DSM) is seen as a potential source of flexibility in the network, enabling efficient use of volatile distributed generation, maintaining network reliability or reducing the cost of supply. The effectiveness of DSM actions largely depends on the flexibility of the demand side. Until now, mostly large industrial users have been included in DSM programs [2]; according to [3], there is more than $500 \mathrm{MW}$ of capacity for short-term operating reserve in the UK. On the other hand, there is a significant, though mainly untapped potential for DSM from the distribution network (DN) comprising mainly of residential users. In the US, it is estimated that residential customers' participation in DSM might bring up to half of the total peak reduction [4]. Taking the UK as an example, residential (domestic) sector is the largest final user of electrical energy, presenting around $30 \%$ of overall consumption, followed by industrial and commercial sector using $26 \%$ and $21 \%$ of the total consumption, respectively [5].
Wide area DSM, i.e. changing the load pattern of a larger number (e.g. hundreds) of end-users simultaneously, will have much larger effect on the network than changing electrical patterns of individual users. This effect will depend not only on the size of the load, but also on its composition (shares of induction motors (IM), resistive loads, etc.). Shifting/curtailing the load will change load composition at the affected hours, and consequently the dynamic response of the aggregated demand, which in turn might affect the angular and voltage stability of the overall power system [6]. It has been long recognized that the power system loads could have significant effect on system stability [7], which is why the load type and composition before and after DSM should be further analyzed.

This paper examines the effect of wide-scale DSM actions on angular stability of the transmission network considering different types and composition of demand and hence different load models to represent each load bus in the network (namely constant impedance, constant power and composite load model) before and after DSM action.

\section{POWER System ANGULAR STABILITY}

Power system angular stability is broadly defined as the ability of interconnected synchronous machines to remain in synchronism after being subjected to small or large disturbances [1].

It is typically assessed and quantified using appropriate stability indices, for example, damping and damping ratio for small-disturbance stability, and transient stability index (TSI) and settling time for largedisturbance stability [8]. In this study, damping of the most critical electromechanical mode (1) and TSI (2) are selected to characterize small and large disturbance stability performances, respectively.

$$
\begin{aligned}
\lambda & =\sigma+\mathbf{j} \omega \\
\text { TSI } & =100 \times \frac{360-\delta_{\max }}{360+\delta_{\max }}
\end{aligned}
$$

In the above equations, $\lambda$ is the eigenvalue of the most critical electromechanical mode in the system, $\sigma$ is the damping of that mode and $\omega$ is the angular frequency of that mode. $\delta_{\max }$ is the maximum angle deviation 
between any two generators in the system during the simulation time. The abovementioned stability indices can quantify corresponding stability performance in such a way that the higher the damping and TSI values are, the more stable system is following small and large disturbances, respectively

\section{SYSTEM MODELLING}

\section{A. Test Network}

The test network adopted in this study is a modified version of IEEE 68-bus NETS-NYPS system, as shown in Fig. 1, which contains 35 loads that have been classified into industrial users (loads with relatively small demand) and DNs (loads with relatively large demand). In total 12 loads (loads 33, 36, 40, 41, 42, 50, 52, 56, 59, 60, 61 and 64) are assumed to be industrial users, and all remaining loads are considered as DNs. Normalized daily loading curves of both industrial users and DNs [9], as well as normalized daily output curves of renewable generators [10], have been added to the test network in order to appropriately account for daily generation and demand variation. Further information about the test system can be found in [11].

\section{B. Uncertainty Modelling}

With the consideration of power system operational uncertainty, uncertainty of wind speed, photovoltaic (PV) output, load demand and fault profile (fault location and fault duration) have been modelled. As shown in Table I, the wind speed follows a Weibull distribution [12] and the PV output follows a Beta distribution [13]. Furthermore, the load demand and the fault duration have been assumed to follow normal distributions with different mean values and standard deviations [14]. Finally, faulted lines and fault locations are selected randomly.

\section{Load Modelling}

In order to investigate the impact of DSM on power system angular stability with different load models, all loads in the system have been modelled as static ZIP load model, consisting of constant impedance (Z), constant current $(\mathrm{I})$ and constant power $(\mathrm{P})$ component (as shown in (3) and (4)), connected in parallel with an induction motor (IM) model.

$$
\begin{aligned}
& P=P_{n}\left(a\left(V / V_{O}\right)^{0}+b\left(V / V_{O}\right)^{1}+c\left(V / V_{O}\right)^{2}\right) \\
& Q=Q_{n}\left(a\left(V / V_{O}\right)^{0}+b\left(V / V_{O}\right)^{1}+c\left(V / V_{O}\right)^{2}\right)
\end{aligned}
$$

$P_{n}, Q_{n}$ and $V_{o}$ are nominal active power, nominal reactive power and nominal voltage, respectively; $a, b$ and $c$ are coefficients for $\mathrm{P}, \mathrm{I}$ and $\mathrm{Z}$ loads, respectively. $\mathrm{IM}$ are modelled as an aggregation of a number of small unit motors with a nominal active power of $5 \mathrm{~kW}$. The load model (load composition and its size) can be adjusted by changing the values of coefficients $a, b$ and $c$ in (3) and (4), and number of unit motors in the aggregated IM model.

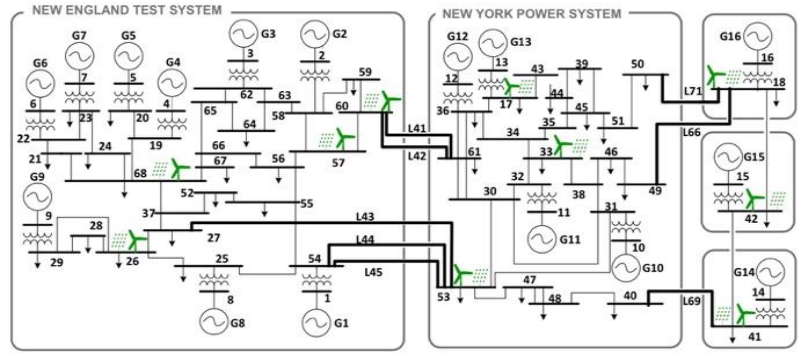

Figure 1. Modified 68 bus NETS-NYPS test system

TABLE I

PROBABILITY DISTRIBUTIONS AND CORRESPONDING PARAMETERS OF SYSTEM INPUT UNCERTAINTIES [12-14]

\begin{tabular}{|c|c|c|}
\hline $\begin{array}{c}\text { Input } \\
\text { Uncertainties }\end{array}$ & $\begin{array}{c}\text { Probability } \\
\text { Distributions }\end{array}$ & Modelling Parameters \\
\hline Wind Speed & Weibull Distribution & $\alpha=2.2, \beta=11.1$ \\
\hline PV Output & Beta Distribution & $\mathrm{a}=13.7, \mathrm{~b}=1.3$ \\
\hline Load Demand & Normal Distribution & $\begin{array}{c}\text { Mean based on load } \\
\text { curves, } \sigma=3.33 \%\end{array}$ \\
\hline Fault Line & Randomly & N/A \\
\hline Fault Location & Randomly & N/A \\
\hline Fault Duration & Normal Distribution & $\begin{array}{c}\text { Mean }=13 \text { cycles, } \\
\sigma=6.67 \%\end{array}$ \\
\hline
\end{tabular}

Due to the existence of two load categories (industrial users and DNs), the load compositions of these categories are modelled separately. The composition of industrial demand is calculated using the information reported in [15] and [16], where IM represent $70-80 \%$ of the total load, constant impedance load represent $10-12 \%$, constant current loads have a share of $7-8 \%$, while the rest is taken to be constant power load. The demand at DN buses is modelled as purely residential and its composition is determined using CREST tool [17]. The example of load compositions for industrial users and DNs are shown in Fig. 2 and Fig. 3, respectively. The figures illustrate the normalized shares of different load components in the total demand at every hour during the day. Based on the demand composition and load categories involved, it has been assumed that all IM and a part of constant impedance loads are controllable; as a result, controllability of each load bus is different at each hour.

\section{THE METHODOLOGY}

\section{A. Probabilistic Analysis Method}

A Monte Carlo based probabilistic analysis method has been implemented in this study. At each simulation hour, system uncertainties are generated in Matlab according to corresponding probability distributions and modelling parameters, and an Optimal Power Flow (OPF) is performed by Matpower [18] to determine the scheduling of synchronous generators [19]. Output results are saved as files for further model analysis in DigSILENT PowerFactory. Two separate Monte Carlo simulations are conducted in DigSILENT PowerFactory at each simulation hour: one for small disturbance stability study and one for large disturbance (transient) stability study. Because of the consideration of system uncertainty and the application of Monte Carlo simulations, a large set of stability indices is produced for both small and large disturbance stability studies at each simulation hour, therefore, some statistic values (mean 
values, most probable values and median values) of corresponding stability indices are adopted to illustrate system angular stability performance at that hour.



Figure 2. Example of demand composition of an industrial load bus [15$16]$

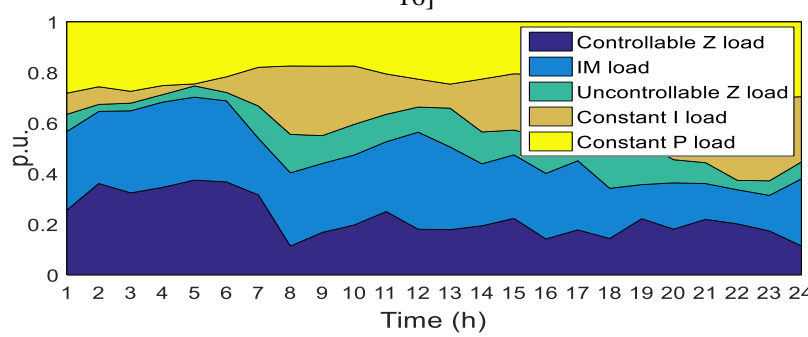

Figure 3. Example of demand composition of a DN load bus [17]

\section{B. Study Cases}

Six case studies have been developed, as shown in Table II, to assess the impact of load models and DSM on system angular stability. Depending on the case study, as depicted in Table II, all loads in the test system are modelled as constant impedance, constant power and composite load model (ZIP and IM). In order to investigate system angular stability with static load models, value of coefficients $c$ in (3) and (4) has been set as 1 , while coefficients $b$ and $c$ are both equal to zero (constant impedance load) in Cases 1 and 2. Similarly, for Cases 3 and 4, values of coefficients $a, b$ and $c$ in (3) and (4) are 1,0 and 0, respectively, to represent constant power loads. There are no IM connected in constant impedance and constant power load models. With the consideration of load dynamics, composite load model is adopted in Cases 5 and 6, in which IMs were reconnected and it has been assumed that each load has a unique combination of $a, b$ and $c$ values in (3) and (4) based on [15-17]. Regardless of the load model used, the DSM potential (shares of the controllable load) follows a predefined hourly pattern at every load bus. For example, if the DSM potential of a bus at certain hour of the day is $50 \%$, it will be $50 \%$ whichever load model is used to represent that bus. The penetration level of renewable generation in all cases has been assumed to be $30 \%$.

\section{DSM Application Methodology}

In this study, the DSM actions are applied with the aim of obtaining a flatter system daily loading profile. Load flattening reduces the number of system balancing actions [20], and the variable cost associated to conventional generation providing regulation services [21]. Therefore, an upper threshold and a lower threshold have been set based on mean system daily load demand. Part of the controllable loads in the system will be disconnected if the total demand is higher than the upper threshold $(1.1 \times$ mean load demand $)$ and they will be reconnected when the total demand is below the lower threshold $(0.85 \times$ mean load demand). The total system loading curves without and with DSM are shown in Fig. 4 as solid line and dashed line, respectively. According to Fig. 4, the loads are disconnected at 10 hours (hours 10 , $11,12,15,16,17,18,19,20$ and 21) and reconnected at 6 hours (hours 1, 2, 3, 4, 5 and 24). Furthermore, it was assumed that no matter how much load (in MW) is curtailed during peak-hours, the same amount of load (in MW) will be reconnected during off-peak hours (providing “energy neutral” DSM over 24 hours).

TABLE II

STUDY CASE

\begin{tabular}{|c|c|c|}
\hline $\begin{array}{c}\text { Case } \\
\text { Number }\end{array}$ & Load Model & DSM Application \\
\hline Case 1 & Constant Impedance Only & No \\
\hline Case 2 & Constant Impedance Only & Yes \\
\hline Case 3 & Constant Power Only & No \\
\hline Case 4 & Constant Power Only & Yes \\
\hline Case 5 & ZIP + IM & No \\
\hline Case 6 & ZIP + IM & Yes \\
\hline \\
\hline
\end{tabular}

Figure 4. Total system loading without/with DSM [9-10]

In Cases 2 and 4, due to the fact that all loads are modelled as constant impedance or constant power loads, the disconnection and reconnection are achieved by changing the active and reactive power of each load $\left(P_{n}\right.$ and $Q_{n}$ in (3) and (4)). As mentioned before, each load has a unique controllability at each hour, therefore, the total DSM capacity at each hour is segmented into 35 different values based on controllability of each load and as a result of that, all loads have different DSM capacity (5) at different hours. The equation used to segment DSM capacities has been shown in (5). Note: DSM potential of a bus refers to the share of controllable load at that bus, while DSM capacity refers to the amount of disconnected load; therefore, DSM capacity is always lower or equal to DSM potential.

DSM capacity at bus $_{i}=\frac{\text { Controllable Load at Bus } i}{\text { Total System Controllable Load }} \times$ DSM capacity (5)

In Case 6, the DSM capacities for each load at each hour have been kept the same as those in Case 2 and 4, however, these are further divided into two values based on the shares of controllable ZIP load (namely controllable $\mathrm{Z}$ load) and IM at that bus, as shown in (6) and (7).

$$
\begin{aligned}
\mathrm{DSM}_{\mathrm{ZIP}} & =\frac{\text { ZIP controllable load }}{\text { controllable load at bus } i} \times \mathrm{DSM} \text { capacity at bus } i \\
\mathrm{DSM}_{\mathrm{IM}} & =\frac{I \text { load }}{\text { controllable load at bus } i} \times \mathrm{DSM} \text { capacity at bus } i
\end{aligned}
$$

For composite loads, DSM actions are achieved by changing active and reactive power and re-calculating 
coefficients $a, b$ and $c$ in (3) and (4). In the case of IM, the aggregation number of small unit motors is changed in order to adjust the total load demand.

\section{RESULTS AND ANALYSIS}

\section{A. Impacts of DSM on Angular Stability with Different Load Models}

As introduced in the previous section, the impact of DSM on system angular stability is assessed by changes of corresponding stability indices before and after DSM. The changes are evaluated using (8), which is applied to both small and large disturbance studies.

Index change $=$ Index before DSM - Index after DSM

The mean values of TSI changes and damping changes with different load models are shown in Fig. 5 and Fig. 6, respectively. It can be seen from Fig. 5 that when the loads are all modelled as constant impedance load, system transient stability performance can be improved at most of the load disconnection hours (8 out of 10 hours except hours 11 and 12). When the disconnected loads are reconnected, system transient stability can be either improved (hours 2 and 24) or deteriorated (hours 1, 3, 4 and 5). In terms of constant power load, system transient stability improvement can be obtained from 7 out of 10 load disconnection hours and 2 out of 6 load reconnection hours. Furthermore, when all loads are modelled using ZIP + IM model, load disconnection can lead to better transient stability performance at 8 out of 10 hours and worse transient stability performance at hours 10 and 18 . Load reconnection will always result in worse transient stability performance in this case. It can be concluded that in all cases the load disconnection mainly improves transient stability indicator and reduces the number of unstable cases, therefore, the overall system transient stability gets improved. The load reconnection on the other hand mainly deteriorated transient stability (compared to the performance before DSM); the extent of the change will vary based on the load model in use.

Fig. 5 shows that during the load reconnection period (hours 1 to 5 and hour 24), the use of ZIP + IM load model results in worse transient stability performance than when constant impedance and constant power load models are used. The system transient stability is the most improved though during the peak hours (hours 17 to 21) if constant power loads are used. In summary, DSM actions (load disconnection and reconnection) could have both positive and negative effects on transient stability. The same DSM action may have completely opposite impacts on transient stability with different load models (hours 2 , 10 to $12,15,18$ and 24). This means that in case of an inappropriate load model, one may under/overestimate the effect of DSM on transient stability indicators in times of load disconnection/reconnection.

System small disturbance stability, as seen in Fig. 6, can be improved at all load disconnection hours for both constant impedance (Case 2) and constant power (Case 4) load models. There is a significant negative effect at hour 1 for these two load models due to the load reconnection,

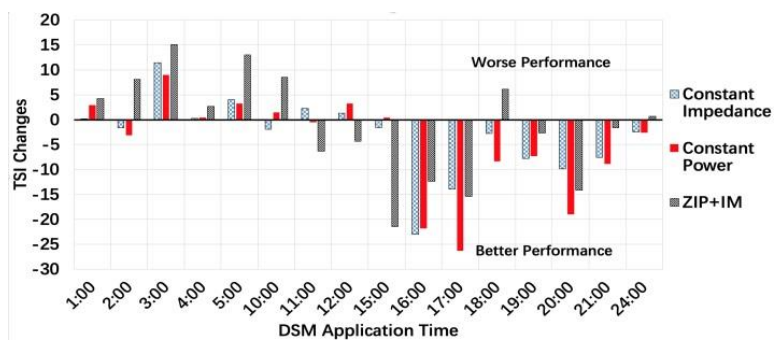

Figure 5. TSI changes with different load model used

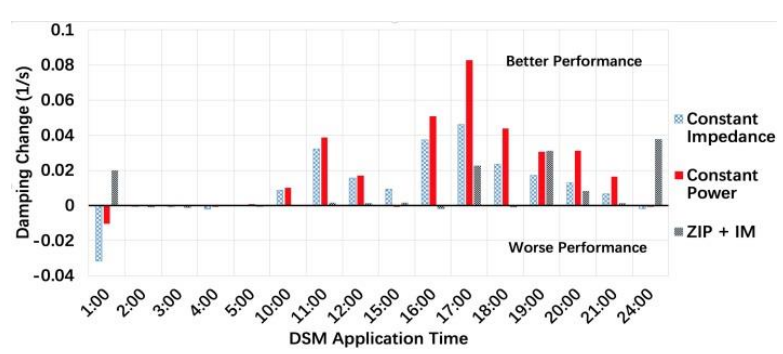

Figure 6. Damping changes with different load model used

but at other load reconnection hours, the impact of load reconnection is negligible. In terms of ZIP + IM load (Case 6), small disturbance stability is improved significantly at hours 1, 17, 19, 20 and 24. For the rest of the DSM application hours, ZIP + IM load has relatively small impact on small disturbance stability.

Focusing on the peak hours (hours 10 to 21 ), it can be seen from Fig. 6 that constant power load model has larger positive effects on the system small disturbance stability performance. Finally, ZIP + IM load model can improve small disturbance stability at hours 1 and 24 , where this type of stability is deteriorated with constant impedance and constant power load models.

Similarly to transient stability study, opposite impacts of DSM on small disturbance stability can be noticed at some DSM application hours, and different load models can lead to very different stability improvement or reduction with the same DSM action. It should be noted though that the system remains small disturbance stable in all study cases.

From the above discussions, DSM actions could either improve or reduce system angular stability (globally or different aspects of it) depending on the system operating condition. Furthermore, the same DSM actions could have completely different, or even opposite impacts on system angular stability depending on the load modelling methodology. In other words, an accurate and appropriate realistic load model is essential to investigate the impacts of DSM on power system angular stability.

\section{B. Impacts of Load Composition on Angular Stability}

Due to the fact that in Case 6, when all loads are modelled as ZIP + IM, the DSM capacity at each bus is divided into two parts (controllable Z load and IM), load composition at each bus before and after DSM actions is different. The shares of dynamic, i.e. IM load (in \%) at Bus 17 during different hours of the day, before and after DSM, are normalized by actual power demand at the respective bus (with the consideration of daily loading 
curves) and shown as an example in Fig. 7. It can be noticed that IM load percentage has increased at load reconnection hours (on average of $1.34 \%$ ) and decreased at load disconnection hours (on average of $0.86 \%$ ). Due to the different IM load percentage (load composition) at each DSM application hour, dynamic response of system demand could be very different when the DSM is applied, which may subsequently lead to different effect of DSM on system angular stability.

For the purpose of investigating to what extend different load compositions change the effect of DSM on system angular stability performance, simulations results in all time steps in Case 6 have been studied. The impacts of DSM on system angular stability with different load compositions have been investigated by percentage changes of TSI and damping, calculated by (9), together with the corresponding mean, most probable and median values. The results for TSI and damping percentage changes (PC) are shown in Fig. 8 and Fig. 9 as adjacent boxplot, respectively.

$$
\mathrm{PC}(\%)=\frac{\text { Result Without DSM-Result With DSM }}{\mid \text { Result Without DSM } \mid} \times 100 \%
$$

In Fig. 8 and Fig. 9, red lines in the middle of boxplots represents the median values of result samples. The bottom and the top of the boxplot are the first and the third quartile values. The difference between these two values has been defined as interquartile range [22]. Furthermore, the line above the boxplot is the upper adjacent value, which is the largest observation from the sample that is less than or equal to the third quartile values plus $1.5 \times$ interquartile range [22]. Similarly, the line below the boxplot is the lower adjacent value, which is defined as the smallest observation from the sample that is larger or equal to the first quartile values minus $1.5 \times$ interquartile range [22]. All sample values larger than upper adjacent value or smaller than lower adjacent values are outliers and are represented by dots in Fig. 8 and Fig. 9.

According to Fig. 8, large interquartile ranges can be found at all load disconnection hours (hours 10 to 12 and hours 15 to 21), which indicates TSI changes have large variation ranges at these hours. This is caused by the reduction of transient stability unstable cases; cases which changed from unstable to stable lead to big variations of TSI values. Furthermore, it can also be concluded that at load disconnection hours load composition plays a higher role in the effect of DSM on TSI compared to the load reconnection hours. In other words, accurate and realistic load compositions are necessary to investigate the exact impact of load disconnection on system transient stability.

Regarding system small disturbance stability performance, large interquartile ranges can only be found at hours 17 (load disconnection) and 24 (load reconnection) based on Fig. 9. At other hours, the range of the percentage change is not as significant. It can be concluded that in most time steps the load composition does not largely affect the changes in damping. In order to further investigate the indices' changes with different load compositions, mean, most probable values and median values of TSI and damping percentage changes are shown

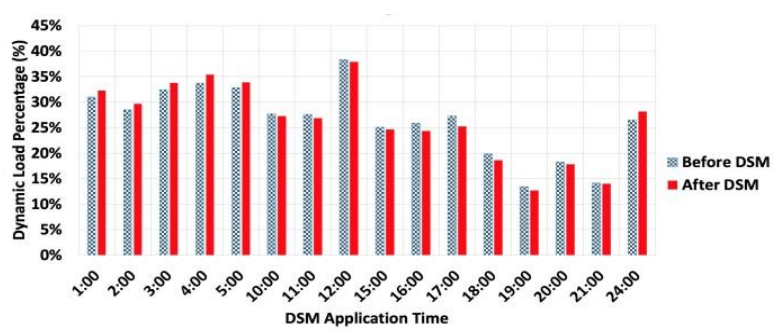

Figure 7. Dynamic load percentage before and after DSM of Bus 17 normalized by actual demand power

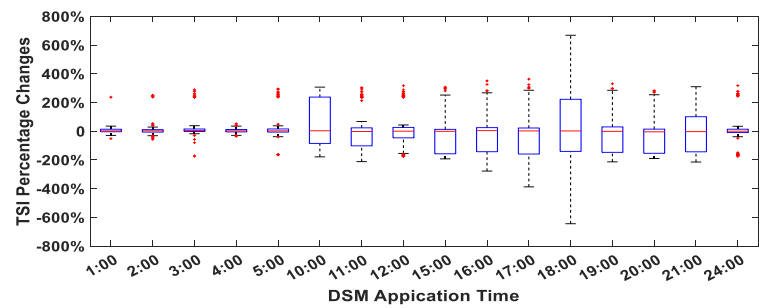

Figure 8. Boxplot of TSI percentage change in Case 6 (ZIP + IM)

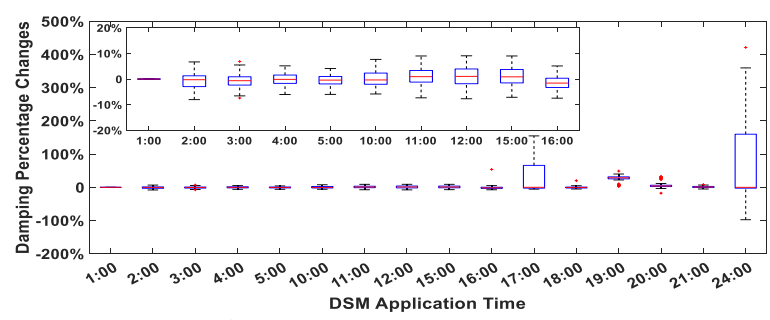

Figure 9. Boxplot of damping percentage change in Case 6 (ZIP + IM)

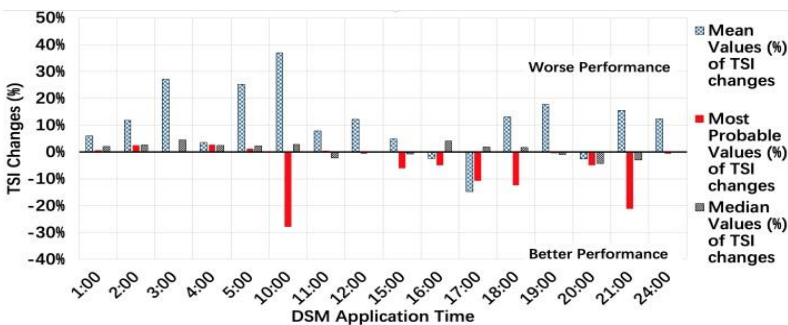

Figure 10. Mean values, most probable values and median values of

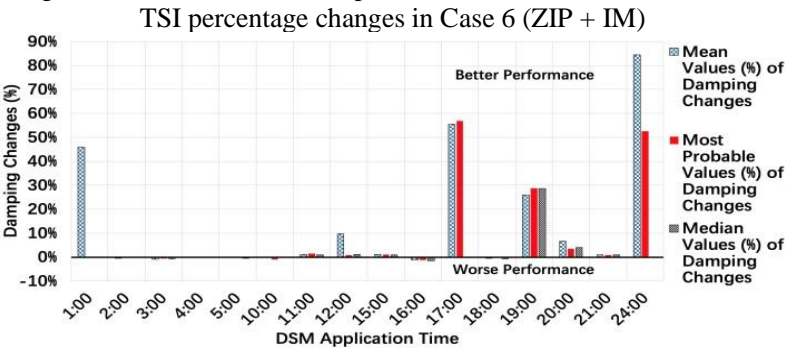

Figure 11. Mean values, most probable values and median values of damping percentage changes in Case 6 (ZIP + IM)

as bar charts in Fig. 10 and Fig. 11, respectively. It can be seen in Fig. 10 that the mean values of TSI changes are positive most of the time, while the most probable values indicate better transient stability performance at 9 out of 10 load disconnection hours, and worse transient stability performance at 5 out of 6 load reconnection hours. Median values of TSI changes show worse transient stability performance at all load reconnection hours and better transient stability performance at 5 out of 10 load disconnection hours. Based on Fig. 11, it can be seen that mean values of damping changes are very high at hours 1 , 17 and 24; similarly, large most probable damping 
changes can be seen at hours 17 and 24. Median values of damping changes are close to zero except at hour 19.

In Fig. 10 and Fig. 11, big difference between mean values, most probable values and median values can be observed at almost all DSM application hours; different statistic values could even indicate completely opposite impacts of DSM on system transient stability. The big difference between abovementioned statistic values means that the system angular stability performance changes significantly due to the varying load compositions at different hours. Accurate and realistic load compositions with corresponding DSM potentials are essential to study if and how much, DSM actions can improve system angular stability. Defining a more detailed relationship between load composition and effects of DSM will be the subject of future studies.

\section{CONCLUSION}

This paper illustrated the effects of load modelling and load composition on assessing the impacts of DSM on power system angular stability. The probabilistic simulation has been performed over 24 hours of a day with the consideration of system uncertainties and different load modelling approaches. It has been found that the same DSM actions (load disconnection/reconnection) may have very different impacts on power system angular stability performance due to the different load models adopted in the study. The size of this impact (positive or negative) is also highly dependent on the load modelling methods.

In terms of load composition, big variations of system angular performances and statistic values of stability indices have been observed with different load compositions, which showed that the load composition has a large effect on system dynamic response. The accurate and realistic modelling of load composition with corresponding DSM potential based on different load types (static and dynamic) are essential to investigate the exact impact of DSM on power system angular stability.

\section{ACKNOWLEDGMENT AND DISCLAIMER}

The research is supported and partially sponsored by the EU H2020 project CROSSBOW (grant agreement 773430) and partly by the school of Electrical and Electronic Engineering of The University of Manchester. The paper reflects only the authors' views and neither the Agency nor the Commission are responsible for any use that may be made of the information contained therein. The test network and the loading scenarios used in this study were originally developed by Dr. A. Adrees and Dr. P. Papadopoulos as part of their research.

\section{REFERENCES}

[1] P. Kundur, J. Paserba, V. Ajjarapu, G. Andersson, A. Bose, C. Canizares, N. Hatziargyrious, D. Hill, A. Stankovic, C. Taylor, T. V. Cutsem and V. Vittal. "Definition and classification of power system stability IEEE/CIGRE joint task force on stability terms and definitions," IEEE Trans. Power Systems, vol. 19, pp. 13871401, May 2004.

[2] K. Samarakoon, J. Ekanayake, and N. Jenkins, "Reporting Available Demand Response," Smart Grid, IEEE Transactions on, vol. 4, pp. 1842-1851, 2013.
[3] M. Woolf, T. Ustinova, E. Ortega, H. O'Brien, P. Djapic, and G. Strbac, "Distributed generation and demand side response," Report A7 for the "Low Carbon London" LCNF project: Imperial College London, 2014.

[4] M. Pipattanasomporn, M. Kuzlu, S. Rahman, and Y. Teklu, "Load Profiles of Selected Major Household Appliances and Their Demand Response Opportunities," IEEE Transactions on Smart Grid, vol. 5, pp. 742-750, 2014

[5] "Digest of United Kingdom Energy Statistics 2015," Department of Energy and Climate Change, [Online].Available:https://www.gov.uk/government/uploads/syste m/uploads/attachment_data/file/450302/DUKES_2015.pdf.

[6] Y. $\mathrm{Xu}$ and J. V. Milanović, "Artificial-Intelligence-Based Methodology for Load Disaggregation at Bulk Supply Point," IEEE Transactions on Power Systems, vol. 30, pp. 795-803, 2015.

[7] Y. V. Makarov, D. J. Hill, and J. V. Milanovic, "Effect of load uncertainty on small disturbance stability margins in open-access power systems," in System Sciences, 1997, Proceedings of the Thirtieth Hawaii International Conference on, 1997, pp. 648-657.

[8] A. B. Ranjit Kumar, V. Brandwajn and A. Ipakchi, "Power system dynamic security analysis using artificial intelligence systems phase 1-feasibility evaluation," Elect. Power Res. Inst., Palo Alto, CA, USA, Apr. 1994.

[9] M. Starke, N. Alkadi and O. Ma. "Assessment of Industrial Load for Demand Response across U.S. Regions of the Western Interconnect," ORNL., Oak Ridge, Tennessee, USA. Sept. 2013.

[10] The University of Edinburgh, "Matching Renewable Electricity Generation with Demand," Scottish Executive, Edinburgh, 2006.

[11] B. Pal and B. Chaudhuri, Robust Control in Power Systems. New York, NY, USA: Springer, 2005.

[12] S. Tao, Y. Ruoying, Z. Lingzhi and G. Shan, "Power system probabilistic production simulation containing large-scale wind power and photovoltaic power," in Proc. IEEE PES Asia-Pacific Power Energy Eng. Conf., Dec. 8-11, 2013, pp. 1-6.

[13] R. Preece and J. V. Milanovic, "Tuning of a damping controller for multiterminal VSC-HVDC grids using the probabilistic collocation method," IEEE Trans. Power Del., vol. 29, no. 1, pp. 318-326, Feb. 2014.

[14] T. Guo and J. V. Milanovic, "Probabilistic framework for assessing the accuracy of data mining tool for online prediction of transient stability," IEEE Trans. Power Systems, vol. 29, no. 1, pp. 377-385, Jan. 2014.

[15] "Modelling and Aggregation of Loads in Flexible Power Networks," CIGRE WG C4.605, 2013.

[16] J.-Y. Lim, J.-H. Kim, J.-O. Kim, and C. Singh, "Application of expert system to load composition rate estimation algorithm," IEEE Transactions on Power Systems, vol. 14, pp. 1137-1143, 1999.

[17] I. Richardson, M. Thomson, D. Infield, and C. Clifford, "Domestic electricity use: A high-resolution energy demand model," Energy and Buildings, vol. 42, pp. 1878-1887, 2010.

[18] R. D. Zimmerman, C. E. Murillo-Sanchez and R. J. Thomas, "MATPOWER: Steady-state operations, planning and analysis tools for power system research and education," IEEE Trans. Power Systems, vol. 26, no. 1, pp. 12-19, Feb. 2011.

[19] P. N. Papadopoulos, T. Guo and J. V. Milanovic, "Probabilistic framework for online identification of dynamic behavior of power systems with renewable generation", IEEE Transactions on Power Systems, Vol. 33, No. 1, Jan. 2018, pp. 45-54.

[20] National Renewable Energy Laboratory. PVWatts Viewer [Online]. Available: http://gisatnrel.nrel.gov/PVWatters_Viewer/index.html.

[21] G. Rogers, Power System Oscillations. Norwell, MA, USA Kluwer, 2000.

[22] "Adjacent Values and Outliers", Docs.tibco.com, 2018. [Online] Available:

https://docs.tibco.com/pubs/spotfire/7.0.1/doc/html/stat/stat_adjace nt_values_and_outliers.htm. [Assessed: 15-Nov-2018]. 